Short report

\title{
Premenstrual periodic paralysis
}

\author{
IDA SAROVA-PINHAS, JACKSON BRAHAM, ARIE SHALEV \\ From the Neurological Department, The Chaim Sheba Medical Center, Tel-Hashomer, and Sackler School \\ of Medicine, Tel-Aviv University, Ramat-Aviv, Israel
}

SUMMARY A 17-year-old girl suffered from episodes of flaccid paralysis during each menstrual cycle. No relevant changes were found in potassium concentrations in serum or erythrocytes, nor in the values of pituitary, ovarian, adrenal or thyroid hormones. Acetazolamide administration prevented the attacks.

Periodic paralysis is the term given to a disorder characterised by attacks of flaccid muscular weakness, usually beginning in childhood or adolescence and recurring at daily to yearly intervals. ${ }^{1-3}$ Between crises there are no signs or symptoms and during the attack objective signs are minimal in comparison with the degree of paralysis; the correct diagnosis is frequently not made at the onset. Although hypokalaemia is the usual concomitant laboratory finding, both hyperkalaemic and normokalaemic varieties have been described. ${ }^{2}$ We report a case of periodic paralysis related to the menstrual cycle, an association which we believe has not been noted previously.

\section{Case report}

IM a 17-year-old girl of Ashkenazy Jewish origin was admitted to the neurological department with flaccid quadriparesis, most severe proximally. She was unable to turn in bed or raise her head. Respiratory and facial muscles were unaffected however and she could swallow and speak freely. Tendon jerks were absent and there was no muscle contraction on tapping; sensation was normal. Several congenital ocular and skeletal defects were also noted, probably attributable to a reported maternal rubella; there was no family history of muscle weakness in three generations.

She reported the regular monthly recurrence from the age of 12 years of pains in the back muscles starting 7-10

Address for reprint requests: Ida Sarova-Pinhas MD, Department of Neurology, The Chaim Sheba Medical Center, Tel-Hashomer Hospital, Israel.

Received 30 May 1981

Accepted 1 August 1981 days before every menstruation and followed gradually by progressive weakness worse in the evening and sufficiently severe to confine her to bed for 2 or 3 days. This state always improved in the next 3 to 4 days, ending spontaneously in the first days of the menses. On the other days of the cycle she experienced no muscular disorder. Paralysis had never occurred in circumstances other than those described. The symptoms started with the first cycle at the age of 12, and had recurred since without exception with every succeeding period. She had been admitted to hospital several times, to the pediatric department; her muscular weakness had been thought to be a neurotic reaction to menstruation. Her present attack ended with the onset of her period with restoration of full muscular power and tendon jerks. Investigations and various therapeutic regimes were carried out subsequently both during and between relapses.

\section{Laboratory examinations}

Blood levels of urea, glucose, chlorides, $\mathrm{CO}_{2}$, calcium, phosphorus, magnesium, cholesterol, uric acid, alkaline phosphatase, protein and protein electrophoresis, creatinine were all normal between and during paralytic episodes. Potassium serum levels ranged from $3 \cdot 2$ to $4 \cdot 4$ $\mathrm{mmol} / \mathrm{l}$ and sodium levels from 133 to $138 \mathrm{mmol} / \mathrm{l}$, and potassium in the erythrocytes $87 \mathrm{mmol} / 1$ to $97 \mathrm{mmol} / \mathrm{l}$. There was no clear correlation between serum or erythrocyte potassium levels and the clinical state, although the lower values were generally noted accompanying phases of paralysis. Serum muscle enzymes (CPK, LDH, SGOT), lactic acid $(0.633 \mathrm{mmol} / \mathrm{l}$ before and $3.15 \mathrm{mmol} / \mathrm{l}$ after ischaemic exercise), and glucose tolerance were all within the usual range. Potassium, sodium, calcium and phosphorus levels in the urine were normal; myoglobinuria or porphyrinuria were not found after exercise or during attacks. Paper chromatography for the amino acids, VMA and 5HIAA was also normal. Thyroid function$\mathrm{T}_{4}(52 \mathrm{ng} / \mathrm{ml}) \mathrm{T}_{3}(5 \cdot 2 \mathrm{ng} / \mathrm{ml})$ and iodine uptake-was 1162 
normal, as were the following endocrine studies: $17 \mathrm{KS}$ $(14.4 \mathrm{mg} / 24 \mathrm{~h}) ; 17 \mathrm{OHCS}(10.6 \mathrm{mg} / 24 \mathrm{~h})$, plasma cortisol $(276 \mathrm{mmol} / \mathrm{l})$, prolactin $(6 \mathrm{ng} / \mathrm{ml} ; 5 \cdot 5 \mathrm{ng} / \mathrm{ml})$, FSH $(2 \cdot 1$ $\mathrm{mIU} / \mathrm{ml})$, LH( $3 \mathrm{mIU} / \mathrm{ml})$, renin $(3 \cdot 3-4 \cdot 4 \mathrm{ng} / \mathrm{ml} / \mathrm{h})$ and aldosterone ( $5 \mathrm{ng} \%$ ). Thyroid, adrenal or renal mechanisms affecting potassium metabolism were therefore considered not to be operative. Daily examination of body temperature showed elevation at the time appropriate for ovulation. Blood levels of progesterone and urinary oestrogens before and after ovulation, repeated during administration of the antiovulatory agent metrolon $\mathrm{n} 50$, were as expected for normal ovarian function. Radiographs of the skull showed normal size of the sella turcica. The ECG on admission showed $U$ waves in $V_{3}$ and $V_{4}$ leads suggestive of hypokalaemia though concomitant serum potassium was $3.4 \mathrm{mmol} / \mathrm{l}$; during the paralytic phase there was T-wave flattening and some VPB's. Nerve conduction velocity and electromyography were normal between attacks; during the days of paralysis no muscle activity was recorded at rest or on attempted volitional contraction. Myasthenic or myotonic reactions were not in evidence.

\section{Treatment}

Administration of $7 \mathrm{~g}$ potassium daily by mouth, or on two other occasions 2 litres of normal saline intravenously, did not relieve muscle weakness. ${ }^{4}$ Potassium in daily oral doses of $5.5 \mathrm{~g}$ was ineffective as prophylaxis, as were antiovulatory tablets over 6 months, although producing the usual changes in progesterone and oestrogen values. Following reports on the use of acetazolamide in periodic paralysis both in hypokalaemic and other types and in spite of the absence of overt hypokalaemia accompanying attacks, it was decided to try this medication. ${ }^{4-8} \mathrm{~A}$ daily dose of $500 \mathrm{mg}$ for the week preceding menstruation successfully prevented the expected attack and was therefore instituted as regular therapy each month. Over a follow-up of more than 3 years there have been no further florid episodes of paralysis except on three occasions when treatment was deliberately interrupted; on each of these, attacks were noted of a severity equal to that in the pretreatment phase. Mild weakness sometimes accompanied intercurrent infections, but was never serious enough to prevent ambulation.

\section{Discussion}

The episodic flaccid paralysis in this girl resembles that seen in classical periodic paralysis. ${ }^{1-3}$ However, apart from the specific relationship to menstruation, other atypical features are the gradual onset and her insensitivity to the usual precipitating factors such as anxiety, cold, rest after vigorous exercise, or heavy carbohydrate meals.

A possible relationship to potassium metabolism is indicated since attacks were associated with some reduction of serum levels, but never to those below the accepted physiological range. The ECG pattern with $U$ waves was however suggestive of hypokalaemia, although the serum potassium was $3 \cdot 4$ $\mathrm{mmol} / \mathrm{ml}$. It has previously been observed that severe changes in the ECG occur in patients with periodic paralysis, which are not seen in normal persons at the same level of serum potassium. ${ }^{9}$ Although the pattern of electrolyte changes in this patient is inconclusive, the beneficial effect of acetazolamide would seem to favour some defect in sodium and potassium inter-relations. ${ }^{56}$ It is possible that acetazolamide prevents her paralytic attacks by a direct effect on skeletal muscle electrolyte transport, ${ }^{10}$ as the drug affects cation exchange and inhibits the movement of potassium from extracellular to intracellular spaces. ${ }^{9}$

Variations in intra and extracellular water balance such as occur in connection with menstrual phases may be postulated, but the precise link between these possible mechanisms and hormonal changes in her menstrual cycle remains unexplained. All endocrine studies gave normal results and furthermore the use of the anovulatory pill proved ineffective in prophylaxis. Bender ${ }^{11}$ reported the case of a girl suffering from periodic paralysis with onset at the menarche, but subsequent attacks were not related to the menses. This specific association in our patient is believed to be unique.

\section{References}

${ }^{1}$ Biemond A, Daniels AP. Familial Periodic paralysis and its transition into spinal muscular atrophy. Brain 1934;57:91-108.

2 Pearson CM, Kalyanaraman K. The Periodic Paralysis. In: Stanbury JB, Wyngaarden JB, Fredrickson DS, eds. The Metabolic Basis of Inherited Disease. Third ed. 1972. McGraw-Hill, A Blakiston Publ. 1181-1203.

${ }^{3}$ Talbott JH. Periodic paralysis: a clinical syndrome. Medicine 1941 ;20:85-143.

${ }^{4}$ Poskanzer DC, Keer DNS. A Third Type of Periodic Paralysis, with Normokalemia and Favourable Response to Sodium Chloride. Am J Med 1961;31 : 328-42.

${ }^{5}$ Griggs RC, Engel WK, Resnick JS. Acetazolamide treatment of Hypokalemic Periodic Paralysis. Ann Int Med 1970;73:39-48.

${ }^{6}$ Reznick JS, Engel WK, Griggs RC, Stam AC. Acetazolamide prophylaxis in hypokalemic periodic paralysis. New Eng J Med 1968;278:582-6.

7 McArdle B. Adynamia episodica heriditaria and its treatment. Brain 1962;85:121-48.

${ }^{8}$ Lewis ED, Griggs RC, Moxley RT. Regulation of plasma potassium in hyperkalemic periodic paralysis. Neurology (Minneap) 1979;29:1131-7.

${ }^{9}$ Grob D, Johns RJ, Liljestrand A. Potassium movement in patients with familial periodic paralysis. Relationship to the defect in muscle function. Am J Med 1957; 23:356-75. 
${ }^{10}$ Streeten DHP. Periodic paralysis. In: Standbury JB, Wyngaarden JB, Fredrickson DS, eds. The Metabolic Basis of Inherited Disease. 2nd ed. 1966. McGraw-
Hill, N.Y. 905-938.

${ }^{11}$ Bender J. Family periodic paralysis in a girl aged seventeen. Arch Neur Psych 1936;35:131-5. 